\title{
LAICIDADE E ESTADO DEMOCRÁTICO DE DIREITO: SOBRE A RELAÇÃO ENTRE DIREITO, RELIGIÃO E O AGIR PRÁTICO ${ }^{1}$
}

Diogo Bacha e Silva ${ }^{2}$

\begin{abstract}
RESUMO: O presente artigo visa abordar a religiosidade e o direito, o Estado e a laicidade, compreendendo a questão da religião em um sentido amplificado de não apenas fé ou crença em divindades. Ademais, o artigo visa também explorar em que medida é possível a convivência entre sociedade secular e confessional no espaço público e qual deve ser a função do Estado Democrático de Direito.
\end{abstract}

Palavras-chaves: Laicidade - Religião - Estado Democrático de Direito.

\section{SECULARISM AND DEMOCRATIC STATE: ON THE RELATIONSHIP BETWEEN LAW, RELIGION AND THE PRACTICAL ACTION.}

\begin{abstract}
This article aims to address the religious and the law, the state and secularis m, including the question of religion in an amplified sense of not only faith or belief in deities. In addition, the article also aims to explore the extent to which the coexistence of secular and confessional society in the public sphere and what should be the role of the democratic state is possible.
\end{abstract}

Keywords: Secularism - Religion - democratic state.

\section{Introdução}

É lugar comum os Estados se declararem laicos, isto é, despidos de qualquer tipo de religiosidade ou norte teológico a orientar a interpretação de seu agir prático. Não obstante, a própria origem da ideia de Estado moderno esteja umbilicalmente ligada à Religião, principalmente a Católica, parece assente a ideia de que, após a Revolução Francesa, os vínculos com a religião foram rompidos.

\footnotetext{
${ }^{1}$ Artigo recebido em 11/06/2015 e aprovado em 13/02/2017.

2 Mestre em Direito Constitucional, Professor Universitário e Coordenador do Curso de Direito da Faculdade de São Lourenço
} 
Em uma sociedade pós-secular, parece que a religião foi colocada em uma redoma de tal modo que não fornece as bases para nossas convicções e, inclusive, deve ser completamente neutralizada.

Há uma espécie de dois lados da relação entre Estado e Religião. Primeiro, o laicis mo que compreende que o Estado deve manter-se inteiramente neutro no que respeita à religião. No outro lado, há o fundamentalismo religioso em que as ações estatais devem ser obedecer aos ditames religiosos.

Nosso artigo visa compreender como é a relação mantida entre constitucionalismo e religião. Como avançamos em relação à manutenção da segregação entre Estado e religião em nosso ideário de constitucionalismo, principalmente a partir da Constituição Federal de 1988? É possível aprendermos com outras experiências constitucionais?

A investigação parte do pressuposto que a religiosidade é parte do nosso agir, parte de nossa compreensão do mundo, inerente ao nosso ser, de nosso mundo da vida, de nosso Dasein. Assumimos, no entanto, que o próprio significado de religião é amplo e depende, efetivamente, do contexto, de nosso uso, de nossa pragmática.

\section{1 - Filosofia e religião: o lugar da religião em uma sociedade pós-secular.}

Tales de Mileto, o primeiro filósofo do mundo grego - ao menos aquele que foi conhecido pela historiografia -, abandonou a doxa de seu pensamento. Fundador da escola jônica, Tales já pensava em um mundo cuja fundamentação residia em uma ordem natural. Seu legado era de que a água, o líquido, constitui o princípio de todas as coisas (REALE; ANTISERI, 1990). De certa forma, o mundo grego afastou a crença de suas considerações sobre o mundo, mantendo somente a busca ordenada por um fundamento.

Apartou-se no pensamento filosófico, então, desde o princípio, a crença e a razão, doxa e episteme. No entanto, o afastamento da doxa não implicava que a filosofia afastasse também de sua análise o pensamento sobre o transcendente. Aliás, o mundo grego não conheceu a separação entre religião, filosofia e moral. Não existia, por assim dizer, um objeto em que cada área do conhecimento deveria se debruçar. 
Na verdade, interpretações da sociedade antiga dizem que é necessário compreender que a religião comanda a vida das pessoas, do nascimento até a morte. Tanto na vida privada onde o pater comandava as ações das mulheres e dos filhos, quanto na vida política antiga, a religião estabelecia vínculos entre os indivíduos. Não havia um único ato que não era objeto de intervenção dos deuses (COMPARATO, 2006).

Mesmo que o nascimento da filosofia tenha sido feito por meio de uma tentativa de explicação racional do mundo, cremos que muitas preocupações que rondavam o pensamento filosófico eram também objeto de preocupação religiosa e estudada por sacerdotes, mas com explicações fundadas em crenças.

Por exemplo, a Summa Teologica de São Tomás de Aquino pretendeu oferecer um discurso sobre Deus. E, obviamente, tudo pode ser encarado do ponto de vista de Deus, inclusive assim diversas questões filosóficas e mesmo jurídicas que brotam da obra de São Tomás de Aquino (COMPARATO, 2006, p. 51).

A separação entre mundo racional e mundo religioso começou a ser preconizada pelo positivismo de Augusto Comte. Sem possibilidade de verificação, a crítica de Augusto Comte é a de que o pensamento religioso de sua época já não poderia mais dar conta da sociedade (COMTE, 1978). Não que Comte tenha afastado a religião da sociedade, mas que o mesmo secularizou a religião, tornando-a verificável, e sacralizou a vida privada, uma vez que a religião seria, assim, a humanidade.

Foi mesmo Nietzsche quem procurou criticar de forma profunda as estruturas religiosas do pensamento (NIETZSCHE, 2011). A partir de suas ideias de Niilismo e da morte de Deus, Nietzsche prega a morte de Deus e o convite a uma vida com outro sentido. O filóso fo ensina que a estrutura judaico-cristã do pensamento ocidental acabou por negar à vida um sentido, deixando- a no completo vazio. Veja-se que, aqui, apresenta um conceito peculiar de Niilismo. Scarlett Marton ensina que: "o niilismo de que o adivinho se faz porta-voz é outro; é a renúncia à vida que ele prega, é a morte em vida que apregoa. Atravessá-la implica aceitar a vida tal como ela é, importa aceitar inclusive tudo o que nela há de mais execrado e infame. Eis o grande desafio que Zaratustra terá de enfrentar. Será preciso coragem para fazer a travessia do nilismo; será preciso coragem para realizar o projeto de transvalorar todos os valores" (MARTON, 1999, p. 137). 
Em outra obra, Nietzsche oferta a interpretação de que todo o pensamento filosófico moderno é cético, no sentido de ser um atentado à concepção da doutrina cristã de $\operatorname{alma}^{3}$. No entanto, apesar de cético quanto à existência da alma, não diz Neitzsche que o pensamento filosófico expurga a religiosidade. Seu martelo dirige-se, assim, ao niilismo praticado pela religiosidade e não propriamente para o sentido de religião.

A fenomenologia heideggeriana, da mesma forma, entende que nosso entendimento é sempre uma abertura ao mundo. O Dasein sempre se abre para compreender o mundo que, também, influencia a compreensão do ser-aí. Uma relação circular, relação que se desenvolve em interdependência mundo e ser. Somos, desde sempre, já seres lançados (Geworfenheit), lançados na nossa própria existência. Nosso privilégio ôntico-ontológico é de mantermos relações com o mundo circundante e podermos perguntar pelo ser (HEIDEGGER, 2012).

Como, então, desvencilharmos da religião em que fomos criados, dos nortes ofertados pela religião? Seria, possível, mantermos distância da religião em nosso mundo da vida? A religião não tem nada a oferecer para a filosofia?

De acordo com Habermas, a palavra "secularização" significou a apropriação dos bens da Igreja para o poder público. De sua origem inicial de transferência compulsória, a palavra secularização significou o surgimento da modernidade cultural e social (HABERMAS, 2013, p. 5). Considera-se, assim, secularização como uma oposição entre, de um lado, ciência e técnica e seu lado progressista e, de outro, as forças conservadoras da religião. A secularização opõe os dois lados com o qual um só irá ganhar se for à custa do outro (HABERMAS, 2013, p. 6).

Em uma sociedade - denominada por Jürgen Habermas - de pós-secular é preciso que encarar uma terceira via entre religião e ciência. Com efeito, comunidades religiosas denominadas de razoáveis renunciam à imposição violenta de sua fé, assimilam que, em

\footnotetext{
3 "Que faz, no fundo, toda a filosofia moderna? Des de Descartes - e antes apesar dele do que a partir do seu precedente - todos os filosófos têm feito um atentado contra o vel ho conceito de alma, sob a aparência de uma crítica ao conceito de sujeito e predicado - ou seja: um atentado contra o pressuposto fundamental da doutrina cristã. A filosofia moderna, sendo um ceticismo epistemológico, é, abertamente ou não, anticristã: embora, diga-se para ouvidos mais sutis, de maneira nenhuma antirreligiosa. Pois antiga mente se acreditava na alma, as sim como se acreditava na gramática e no sujeito gramatical: dizia-se que "eu" é condição, "penso" é predicado e condicionado - pensar é uma atividade para a qual um sujeito tem que ser pensado como causa. Tentou-se, então, com tenacidade e astúcia digna de admiração, enxergar uma saída nessa teia - se não seria verdadeiro talvez o contrário: penso, condição, eu, condicionado; eu sendo uma síntese, feito pelo próprio pensar" (NIETZSCHE, 2005, . p. 53).
} 
sociedades plurais, deve haver o encontro cognoscitivo entre outras religiões e, também, devem se adaptar ao fato de que o Estado Constitucional levanta uma moral profana (HABERMAS, 2013, p. 6-7).

A partir disso, quando questões relevantes vão para agenda política, os cidadãos, sejam crentes ou não, acabam por colidir suas convicções impregnadas de visões de mundo diferentes com outras visões de mundo dissonantes. Quando, então, lidam pacificamente com este conflito público, reconhecendo a falibilidade de sua visão de mundo, aí sim se tem a tomada de decisão secular de acordo com as condições estabelecidas pela Constituição e o aprendizado da moral profana do Estado Constitucional.

O aprendizado recíproco entre fé e razão, entre religião e filosofia, possibilita a diminuição daquilo do risco de um choque de civilizações (clash of civilisations) e das mordernidades múltiplas que podem ocorrer dentro da própria fronteira do Estado Constitucional, tanto quanto na arena internacional. Para tanto, é preciso compreender que tanto os cidadãos seculares dos Estados quanto a comunidade religiosa devem compreender que em uma sociedade pós-secular há a necessidade de sobrevivência de comunidades religiosas (HABERMAS, 2007, p. 158).

Cidadãos seculares precisam compreender que as discordâncias com as visões de mundo religiosas será um dissenso razoável esperado pelo uso da razão pública. O verdadeiro ethos dos cidadãos em sociedades pós-seculares será, portanto, tanto os seculares como os religiosos, passarem por processos de aprendizagem recíprocos (HABERMAS, 2007, p. 158).

Significa isso que não precisamos nos desvencilhar de nosso mundo da vida que, obviamente, inclui a religião, mas que precisamos saber atuar com uma ética plural, sabedor que há discordâncias entre cosmos visões e que não é possível impormos a fé mediante a violência.

\section{2 - Estado e religião: sobre o sentido de um agir prático laico}

O absolutismo monárquico do Ancién Regimen, na Europa do século XVI até meados do século XVIII, foi quem inicialmente buscou uma separação política entre Estado e Igreja. Caracterizado pelo poder jurídico ilimitado dos reis que se encontravam acima de qualquer jurisdição (princeps legibus solutus), também as igrejas nacionais e o clero foram compelidos 
a aceitar o jugo das autocracias (CAENEGEM, 2009,p. 121). Assim como as Igrejas foram sendo paulatinamente afastadas do jogo político do Estado moderno, crescia também um apelo por uma homogeneidade religiosa e a ideia de que o poder profano devia sua causa às bases sobrenaturais. O rei seria o representante de Deus na terra.

A intolerância bem caracterizada pela revogação do Édito de Nantes de 1585 por Luis XIV em 1685(CAENEGEM, 2009, p. 124) demarca bem o período de aliança entre uma religiosidade homogênea social e o exercício do poder político. Por exemplo, na França apenas Henrique II consegue firmar paz entre os conflitos religiosos dando um abrandamento na extensão da doutrina calvinista do velho princípio: une foi, une loy, un roi (MATTEUCCI, 1998, p. 43). Nessa medida, o Estado moderno acredita firmemente no princípio de redução da sociedade a uma única religião. Os princípios reitores do cristianismo são os mesmos que orientam a ação política do Estado.

Não por outra razão, o contratualismo, principalmente de John Locke, vai se insurgir contra a assunção política da religião. A partir de sua obra Cartas sobre a Tolerância, John Locke empreende uma verdadeira crítica a imiscuída relação entre Igreja e Estado. Para ele, então, a comunidade deve estar preocupada com as questões civis, entendida estas coisas como vida, liberdade, igualdade, propriedade. A igreja deve se preocupar com a salvação da alma. A verdadeira religião não se impõe pela força, pela lei, mas pela fé, pela crença (LOCKE, 1999). Deve haver uma separação entre Estado e Igreja. Àquele cabe assuntos de ordem pública e cabe proteger os bens individuais. A esta, reunida sob o pálio da vontade dos homens, cabe apenas a exortação a Deus e é assunto da consciência de cada um.

Conforme afirma Fabio Konder Comparato, John Locke, ao sustentar que a religião era assunto de cada indivíduo, não afirmou que o Poder Público devia se desinteressar por completo da questão, já que as diferenças entre convicções religiosas alimentaram lutas e guerras entre os particulares. A tolerância invocada por John Locke não é apenas um assunto de virtude moral, mas sim um deve jurídico correspondente a um direito natural de todos: professar livremente sua conviç̧ão religiosa (COMPARATO, 2006, p. 212).

No entanto, apesar de pregar a liberdade na convicção, John Locke acaba por afirmar que é permitida a intolerância em relação aos ateus, uma vez que estes, ao negar Deus, também nega o vínculo social que nos une. Permitir-se-ia, assim, a intolerância em relação a estes. Negando-se lhes, pois, os direitos fundamentais básicos (LOCKE, 1999). 
Prega John Locke um conceito de religião que está ligada ao culto de alguma divindade e o estabelecimento de dogmas. A liberdade religiosa, assim, estar-se-ia também ligada à veneração e o culto de alguma divindade. Fora de tal hipótese não poderia haver liberdade religiosa.

O Estado moderno, assim como pensado pelos contratualistas, tem como marco a proteção da liberdade religiosa em um sentido positivo, isto é, a premissa de que a liberdade religiosa só abrange àqueles indivíduos que professarem uma crença em uma divindade. Por exemplo, tal acepção foi positivada na primeira Constituição Francesa de 1791 no art. $3^{\circ}$ que dispunha: "liberdade para todo homem [...] exercer o culto religioso ao qual esteja ligado".

Também a primeira emenda à Constituição norte-americana (1791) estabelece uma liberdade religiosa positiva. Estabeleceu-se, assim, a "establishment clause" em que se proíbe ao Estado Norte-Americano a assunção de alguma concepção religiosa, bem como a "free exercise clause" onde há uma obrigatoriedade do Estado abster-se de proibir o exercício de qualquer religião. De fato, Jellinek até concebe a ideia da liberdade religiosa nas colônias norte-americanas origina a consagração jurídica de um direito universal dos homens (WEINGARTNER NETO, 2013, p. 267). Mesmo que por suas contingências históricas, a sociedade norte-americana sempre levou a sério a questão da liberdade religiosa.

No Brasil, mesmo com a Independência, durante o Império (1822-1889) assumimos uma fase denominada confessional. $\mathrm{O}$ art. $5^{\circ}$ da Constituição do Império de 1824 dispunha que: “A Religião Católica Apostólica Romana continuará a ser a religião do Império. Todas as outras Religiões serão permitidas com seu culto domestico, ou particular em casas para isso destinadas, sem forma alguma exterior do Templo".

Nessa medida, o Estado brasileiro assumiu uma religião oficial, a Católica Apostólica Romana. Esta seria a religião do espaço público. A religião que ostensivamente poderia ser praticada por todos. Toda e qualquer outra religião praticada devia se ater ao espaço privado, ao espaço da intimidade dos indivíduos. A religião Católica seria própria da rua, enquanto que as demais seriam próprias da casa, para dizer com Roberto da Matta.

Assim, as escolas, órgãos públicos, hospitais, etc., incorporavam em seus estabelecimentos a religião Católica. Qualquer outra religião era deixada no não dito, no silêncio da vida privada, da vida íntima. 
Nosso Direito, portanto, devia ser constituído também de acordo com as premissas religiosas abraçadas por nosso Estado. $\mathrm{O}$ agir prático do Estado deveria estar em completa consonância com as premissas religiosas do catolicismo. Diferentemente do contexto norteamericano, cujo Estado já nasce com a liberdade religiosa, o Brasil assume uma forma hibrida, comungando a liberdade religiosa e uma religião oficial.

Apenas com a Proclamação da República em 15 de Novembro de 1889 que se pensou em laicizar o Estado Brasileiro. Através do Decreto n. 119-A de 07 de janeiro de 1990, promulgado durante o Governo Provisório, ficou expressamente proibida à União e Estados estabelecer uma religião oficial ou, ainda, criar diferenças entre os habitantes no país em virtude de crença religiosa: “Art. $1^{\circ}$ É proibido à autoridade federal, assim como à dos Estados federados, expedir leis, regulamentos, ou atos administrativos, estabelecendo alguma religião, ou vedando-a, e criar diferenças entre os habitantes do país, ou nos serviços sustentados à custa do orçamento, por motivo de crenças, ou opiniões filosóficas ou religiosas". Referido decreto marca o rompimento do Estado brasileiro com a Igreja Católica (MORAIS, 2011, p. 236).

Assumido pela Constituição de 1891 como direito individual, a liberdade religiosa e o compromisso de um Estado laico aparecem em todas as demais Constituições brasileiras (1934, 1937, 1946, 1967, 1969). Logo no contexto da república velha, as relações entre Estado e religião ficaram estabelecidas pelas seguintes normas:

a) vedava aos estados e à União estabelecer, subvencionar, ou embaraçar o exercício de cultos religiosos (art.11, n.2);

b) vedava o alistamento eleitoral (aos pleitos federais e estaduais) dos religiosos de ordens monásticas, companhias, congregações, ou comunidades de qualquer denominação sujeitas a voto de obediência, regra ou estatuto, que importe renúncia da liberdade individual (art.70, n.4);

c) assegurava a liberdade religiosa a todos os indivíduos e confissões, que poderiam exercer pública e livremente o seu culto, associando-se para esse fim e adquirindo bens, observadas as disposições do direito comum (art.72, n.3);

d) dispunha que a República reconheceria apenas o casamento civil, cuja celebração seria gratuita (art.72, n.4); 
e) determinava a secularização dos cemitérios, que viriam a ser administrados pela autoridade municipal, ficando livre a todos os cultos religiosos a prática dos respectivos ritos em relação aos crentes, desde que esses não ofendessem a moral pública ou as leis (art.72, n.5);

f) dispunha que o ensino ministrado nos estabelecimentos públicos deveria ser leigo (art.72, n.6);

g) estabelecia que nenhum culto ou igreja gozaria de subvenção oficial, nem teria relações de dependência ou aliança com o governo da União, ou o dos estados (art.72, n.7);

h) assegurava que, por motivo de crença ou função religiosa, nenhum cidadão brasileiro poderia ser privado de seus direitos civis e políticos, nem eximir-se do cumprimento de qualquer dever cívico (art.72, n.28);

i) dispunha que os que alegassem motivo de crença com o fim de se isentarem de qualquer ônus que as leis da República impusessem aos cidadãos perderiam todos os direitos políticos (art.72, n.29).

Nessa medida, como alerta Fabio de Carvalho Leite, as normas jurídicoconstitucionais consagradoras da laicidade estatal apresentavam uma dissensão, uma indefinição entre os próprios especialistas, que marcou o período republicano. A partir de uma sociedade profundamente católica e um sentimento extremamente religioso vigorante no meio social na época, o texto constitucional permitiu uma acomodação à Igreja Católica, ocupante de um importante espaço social na sociedade (LEITE, 2011, p. 45).

Por isso que, por mais que grassem interpretações no sentido da instalação de uma laicidade logo com a República Velha, é bem verdade que, em virtude de nosso próprio mundo da vida, da cotidianidade de nosso ser, marcados indelevelmente pela influência da Igreja Católica na formação de nosso Estado, tem-se que a primeira república não se tornou um Estado laico da noite para o dia.

Em primeiro lugar, perseguições religiosas eram práticas comuns no período republicano. Minorias religiosas como evangélicos sofreram por parte dos católicos e, eventualmente, endossados pelas autoridades, a possibilidade de invasão de templos, queima de bỉblias e ataques a pastores. Espíritas também tiveram suas práticas religiosas consideradas como criminosas pelo Estado (LEITE, 2011). 
Ademais, menção a Deus nas Constituições, crucifixos e imagens religiosas em prédios públicos, manutenção de cemitérios por parte de entidades confessionais, quando havia expressa disposição constitucional atribuindo sua administração ao Poder Público Municipal e ensino religioso nas escolas faziam parte do paradoxo em que vivia a sociedade republicana brasileira.

A promulgação da Constituição de 1988 pouco alterou esse quadro. Do ponto de vista normativo, a Constituição de 1988 , em seu art. $5^{\circ}$, inc. VI, estipulou a liberdade de consciência e de crença nos seguintes termos: "É inviolável a liberdade de consciência e de crença, sendo assegurado o livre exercício dos cultos religiosos e garantida, na forma da lei, a proteção aos locais de culto e suas liturgias". Por tal artigo, assegurou-se a liberdade de crença negativa e a positiva. Pela primeira, o Estado não poderá criar embaraço para o exercício de qualquer crédulo religioso, enquanto que na segunda assegura-se ao indivíduo a crença em uma divindade e professar a respectiva fé, mesmo que no espaço público.

No art. $5^{\circ}$, incisos VII e VIII, contemplam-se direitos individuais para a profissão de fé: "VII - é assegurada, nos termos da lei, a prestação de assistência religiosa nas entidades civis e militares de internação coletiva". De outro lado, "VIII - ninguém será privado de direitos por motivo de crença religiosa ou de convicção filosófica ou política, salvo se as invocar para eximir-se de obrigação legal a todos imposta e recusar-se a cumprir prestação alternativa, fixada em lei”. Duas garantias do indivíduo que, nos termos do art. $5^{\circ}$, inc. VII, garante que o Estado prestará assistência religiosa, e, no inc. VIII, que o Estado não poderá impelir o indivíduo a fazer algo em desacordo com sua fé.

Ainda, o art. 19, inciso I estipula que é vedado à União, Estados, Distrito Federal e Municípios embaraçar o funcionamento de estabelecimento religioso ou manter alianças com os mesmos ou suas lideranças, exceto por motivo de interesse público. De igual sorte, o art. 150, VI, alínea b garante a imunidade tributária de impostos sobre templos de qualquer culto quanto aos seus bens, seu patrimônio e sua renda, desde que sejam relacionados às atividades essenciais das entidades religiosas.

Por último, nossa Constituição de 1988 faculta o ensino religioso nas escolas públicas de ensino fundamental no art. $210, \S 1^{\circ}$.

A Constituição estabelece uma garantia de liberdade religiosa onde cada indivíduo poderá professar sua religião, seja em espaço público ou privado, de tal modo a que não sofra 
a interferência estatal. O Estado não poderá imiscuir-se em assuntos religiosos, podendo apenas estabelecer relações que sejam do interesse de todos.

Nesta esteira, a Constituição apesar de normatizar e tentar estabelecer um Estado laico, não consegue manter uma separação entre Estado e religião. Seja porque não se consegue separar o ser-no-mundo do agente público com sua religiosidade, seja porque há uma cooptação religiosa da esfera política. Não que isso seja maléfico para o Estado. A questão toda é como o Estado democrático deverá lidar com a participação da religiosidade na esfera pública.

Segundo Habermas, o Estado moderno não depende de legitimações religiosas, apenas uma razão humana acessível a todos constitui a justificação do poder político (HABERMAS, 2007, p. 135). É preciso que a Constituição democrática assuma as funções que outrora foram dos argumentos religiosos. Como meio integrativo entre esfera secular e esfera religiosa, a Constituição determina parâmetros de conduta para os indivíduos. A Constituição, em sua contrafacticidade, estabelece razões para o agir do Estado e dos indivíduos.

Assim, conforme estabelece Habermas, "os cidadãos religiosos, como também os seculares, devem saber interpretar, cada um na sua respectiva visão, a relação entre fé e saber, porquanto tal interpretação prévia lhes abre a possibilidade de uma atitude auto-reflexiva e esclarecida na esfera pública política" (HABERMAS, 2013, p. 167). Ao Estado cumpre, então, ser neutro no que diz respeito às visões de mundo. Sem, no entanto, renunciar a autonomia, permanece em aberto para aprender com ambas as partes do conflito, desde que com o uso da razão pública (HABERMAS, 2013, p. 8).

O agir prático do Estado, para ser laico, portanto, deve observar e fazer possível a integração entre as duas partes do conflito, desde que ambas estejam em condições de um aprendizado recíproco.

\section{3 - Direito e religião: contornos hermenêuticos da liberdade religiosa em um} Estado Democrático de Direito

O Direito, além de ser razão teórica, também é razão prática. Como a razão humana prática busca determinar a vontade e, assim, ter uma realidade objetiva (REALE, ANTISERI, 
2003, p. 901), necessário saber o conteúdo do conceito de religião, principalmente buscando resolver problemas concretos surgidos nos limites da liberdade religiosa.

Problemas demarcando a liberdade religiosa são enfrentados pela jurisprudência, tanto no espaço público quanto no espaço privado. Por exemplo, a Corte Europeia de Direitos Humanos considerou, no caso Kokkinakis vs. Grécia de 1993, que a condenação por crime de proselitismo configura ofensa à liberdade religiosa que também abrange a possibilidade do indivíduo tentar convencer o próximo. Assim, tem-se que a liberdade religiosa assume sim uma importante função na esfera pública, não podendo ser desconsiderada como queria John Locke.

Mesmo na esfera privada, a liberdade religiosa ainda tende a ser defenestrada pelo Estado. Basta ver, por exemplo, a proibição de utilização de véus islâmicos em alguns países europeus. Tal ato foi referendado pela Corte Europeia de Direitos Humanos que, no caso Dahlab vs. Suíça (2001), julgou possível a um Estado Democrático proibir a utilização de lenços islâmicos se a sua utilização for considerada incompatível com a ordem pública e a segurança pública.

O que, então, o direito considera como religião e, portanto, possível a proteção pela liberdade religiosa em um Estado Democrático.

Há, inclusive, juristas que consideram que é impossível formular um Estado neutro, despido de valores. Assim, "não só o indivíduo que recorre a Deus para construir a sua identidade. Não é apenas a cultura que se manifestar incuravelmente religiosa. Também o Estado Constitucional pressupõe a existência de Deus, mesmo que implicitamente, para garantir sentido e fundamento racional aos seus valores e princípios, considerados universais e indisponíveis pelos Estados, pelas Constituições e pelos tratados internacionais" (MACHADO, 2013,p. 153). O autor propõe que a neutralidade religiosa do Estado Constitucional não pode comprometer nem os indivíduos ateus, nem promover qualquer hostilidade à religião. A matriz teísta do Estado Constitucional é a de que o mesmo deve propiciar a todos o cumprimento de suas obrigações religiosas (MACHADO, 2013, p. 144).

Tem razão o autor de propugnar que o Estado Constitucional deve possibilitar o exercício da religião e de que não é permitida a exclusão em absoluto da religiosidade da vida pública. No entanto, afirmar que os valores albergados pelo Estado somente advém de sua matriz judaico-cristã e que os ateus não conseguem justificar a universalidade e a primazia de 
tais valores, uma vez que propõem uma visão irracionalista e acidentalista do mundo e que, ao destituir tais valores, cairíamos em um subjetivismo, no arbítrio e na precariedade das construções sociais, mesmo com a adesão de visões religiosas de tipo politeísta (MACHADO, 2013, p. 171-172) é demasiado exagerado e pressupõe uma interpretação que, no limite, pode levar à intolerância com a exclusão de outras visões de mundo.

O próprio termo "tolerância" foi cunhado a partir do francês e do latim no âmbito dos grandes conflitos religiosos dos séculos XVI e XVII. Inicialmente, a palavra significa va uma concessão a outras confissões religiosas. A partir disso, o direito passa a incorporar tal preceito como ato jurídico das autoridades que toleram que pessoas e práticas de outras crenças se estabeleçam na sociedade (HABERMAS, 2007, p. 279). Sua significação, assim, passa a ser entendida como dirigida a destinatários religiosos e uma transigência das autoridades.

Ora, a questão então soa paradoxal: a tolerância é um ato de permissão que inclui o fato de estabelecer limites nas práticas religiosas, trazendo assim uma mácula de uma exclusão na inclusão. Permite-se, de cima para baixo, práticas religiosas. Outras práticas religiosas, no entanto, não são consideradas moralmente aceitas.

Assim, tolerância é também intolerância. Algumas práticas religiosas são "toleradas", isto é, juridicamente possíveis, mas moralmente estranhas. Como, então, fazer com que a liberdade religiosa seja amplamente garantida no Estado Democrático de Direito.

Basta citarmos que, por exemplo, mesmo as Constituições garantindo a liberdade religiosa, houve muitas criminalizações de espíritas pelo crime de curandeiris mo ${ }^{4}$. A "tolerância" apenas permite práticas consideradas normais pela maioria.

Para compreendermos a liberdade religiosa e sabendo que estamos inseridos em um mundo da vida que dita nossa interpretação, é preciso considerarmos que, para uma convivência pacífica de diferentes comunidades religiosas, deve haver uma renuncia a meios de coação política para imposição de fé, bem como a eliminação de qualquer tipo de coação moral contra os próprios membros das confissões religiosas (HABERMAS, 2007, p. 282). A

\footnotetext{
${ }^{4}$ Por exemplo, HC 62.240/SP, rel. Min. Francisco Rezeck, j. 13.12.1984 em que um espírita fora condenado por curandeirismo. Alegou o STF que suas práticas não poderiam ser enquadradas na liberdade religiosa, uma vez que os fatos se apresentavam inconfundíveis com a prática da religião. Obviamente por nos faltar conhecimento profundo do caso não podemos tecer considerações críticas, mas, obviamente, nos parece que, em sendo assim, muitas religiões práticas católicas também deviam ser consideradas curandeirismo. Entrementes, trata-se de religião tratada como normal, dentro dos parâmetros da sociedade brasileira.
} 
tolerância no Estado Democrático de Direito se não é uma ética primeira levinasiana no sentido de alteridade, pelo menos deve ser o respeito ao outro como co-cidadão, "mesmo quando avaliamos a sua fé ou seu pensamento como falsos ou rejeitamos a correspondente conduta de vida como ruim" (HABERMAS, 2007, p. 286).

Neste ponto, deve ter um respeito pelo ethos do outro. Mesmo que a religião seja uma forma de vida em sua totalidade, em sociedades pluralistas e democráticas, a religião deve renunciar a pretensão de a tal pretensão, já que a vida da comunidade política é mais ampla do que a vida da comunidade religiosa. Por isso é que os fundamentalistas religiosos que pregam o desrespeito às outras visões de mundo não conseguem assumir as premissas do Estado Democrático de Direito e permite, assim, que o direito possa reagir diante de tal atitude.

Somente na sociedade em que cada um considera o próximo com igual e respeito e consideração, incluindo aí a assunção de visão de mundo diferente, religião diferente pode se constituir como Estado Democrático.

É preciso entender que os conceitos definidos na Constituição não dependem de um entendimento comum ou definição lexical no dicionário. Como diz Dworkin, conceitos constitucionais são conceitos interpretativos que nós devemos decidir o que proteger como direitos humanos e constitucionais e defini-los, de modo que faça sentido e tenha uma papel crucial na implementação da igualdade (DWORKIN, 2013, p. 109).

A liberdade religiosa pode ser justificada no fato de que cada "pessoa tem uma inescapável e intrínseca responsabilidade ética de fazer de sua vida ser bem sucedida" ${ }^{5}$. Esta responsabilidade, como nos ensina Dworkin, é algo que tanto crentes quanto ateístas podem compartilhar.

A Suprema Corte Norte-Americana, por exemplo, considera como passível de proteção pela cláusula de objeção de consciência indivíduo ateísta, cujas convicções morais proibiam de participar do serviço militar ${ }^{6}$. Uma sincera e significativa crença que ocupa, portanto, na vida do indivíduo possuidor tem um lugar paralelo àquele que seria reservado para Deus ou outra divindade e qualifica-se dentro da definição de objeção de consciência.

\footnotetext{
${ }^{5}$ No original: "[...] ]each person has na intrinsic and inescapable ethical responsibility to make a sucesso f his life" (DWORKIN, 2013. p. 109).

${ }^{6}$ United States vs. Seeger, 380 US 163 (1965).
} 
O papel de um Estado Democrático de Direito é deixar com que cada indivíduo usufrua de sua liberdade, deixando os cidadãos por si mesmos decidirem quais questões são melhores para fazer de sua vida ser bem sucedida e não impor qualquer questão ou visão de mundo (DWORKIN, 2013, p. 130).

Assim, religião e Estado podem conviver na esfera pública, desde que as premissas da pluralidade de visões de mundo sejam corretamente seguidas.

\section{Conclusão}

A religião faz parte de nossa visão de mundo. Portanto, a laicidade deve ser bem compreendida no atual paradigma de Estado Democrático. Nosso agir prático compreende não só a esfera privada, mas também a esfera pública. A religiosidade não tem como ser cindida de nossa visão de mundo. Isto, no entanto, não significa que devemos impor nossas considerações de fé para os demais membros das comunidades, a quem tratamos com igualdade e respeito.

Ora, a crença é algo constitutivo do ser. Mas qual o limite da religiosidade para o direito? Demonstramos no artigo que é possível o aprendizado entre indivíduos seculares e religiosos. A esfera pública permite e incentiva que a razão pública seja dotada de argumentos dos dois lados.

A tolerância religiosa, entrementes, não pode significar uma imposição arbitrária de alguma religiosidade em favor de outra. Ao Estado Democrático de Direito incumbe possibilitar que todos os indivíduos usufruam da liberdade de assumir a visão de mundo que melhor possibilitem fazer com que a vida seja bem-sucedida, no sentido de um valor a ser buscado individualmente. Tanto valores teístas quanto ateístas são abraçados pelo Direito e devem fazer parte de nosso agir prático.

\section{Referências}

CAENEGEM, R.C. van. Uma introdução histórica ao Direito Ocidental Ocidental. Lisboa: Fundação Caloust Gulbenkian, 2009. 
COMPARATO, Fabio Konder. Ética: direito, moral e religião no mundo moderno. $2^{a}$ ed. São Paulo: Companhia das letras, 2006.

COMTE, Auguste. Curso de Filosofia Positiva. In: Os Pensadores:Comte. São Paulo, Abril Cultural, 1978.

DWORKIN, Ronald. Religion without God. Cambridge: Harvard University Press, 2013.

HABERMAS, Jurgen.. Entre naturalismo e religião: estudos filosóficos. Rio de Janeiro: Tempo Brasileiro, 2007.

HABERMAS, Jürgen. Fé e saber. São Paulo: Editora Unesp, 2013.

HEIDEGGER, Martin. Ser e tempo. $6^{\text {a }}$ ed. Petropólis: Vozes, 2012.

LEITE, Fabio de Carvalho. O Laicismo e outros exageros sobre a Primeira República no Brasil. Religião e Sociedade, Rio de Janeiro, 31 (1) : 2011.

LOCKE, John. Carta sobre a tolerância. Lisboa: Editora Lisboa, 1999.

MACHADO, Jónatas. E. M. Estado Constitucional e neutralidade religiosa: entre o teísmo e o (neo) teísmo. Porto Alegre: Livraria do advogado, 2013. p. 144.

MARTON, Scarlett. A morte de Deus e a transvaloração dos valores. HYPNO, ano 4, n. 5, 1999, São Paulo, p. 133-143.

MATTEUCCI, Nicola. Organización del poder y libertad: historia del constitucionalismo moderno. Madri: Trotta, 1998.

MORAIS, Marcio Eduardo Pedrosa. Religião e Direitos Fundamentais: o princípio da liberdade religiosa no Estado Constitucional Democrático Brasileiro. Revista Brasileira de Direito Constitucional-RBDC n. 18 - jul./dez. 2011.

NIETZSCHE, Friedrich. Além do bem e do mal. São Paulo: Companhia das letras, 2005.

NIETZSCHE, Friedrich. Assim falou Zaratustra. São Paulo: Companhia das letras, 2011.

REALE, Giovanni; ANTISERI, Dario. História da Filosofia. Vol. I. São Paulo: Paulus, 1990.

REALE, Giovanni; ANTISERI, Dario. História da Filosofia. Vol. II. São Paulo: Paulus, 2003. 
VILLEY, Michel. A formação do pensamento jurídico moderno. $2^{\mathrm{a}}$ ed. São Paulo: WMF Martins Fontes, 2009.

WEINGARTNER NETO, Jayme. Comentários ao art. 5\%, incs. VI a VIII. In: CANOTILHO, J. J. Gomes; MENDES, Gilmar Ferreira; SARLET, Ingo Wolfgang; STRECK, Lenio Luiz. (Coords.) Comentários à Constituição do Brasil. São Paulo: Saraiva, 2013. 